\title{
Health Consequences of Online Social Capital among Middle-Aged and Older Adults in China
}

\author{
Junfeng Jiang ${ }^{1} \mathbb{D} \cdot$ Jiang Song ${ }^{2}$
}

Received: 2 July 2021 / Accepted: 22 December 2021 / Published online: 8 January 2022

(c) The International Society for Quality-of-Life Studies (ISQOLS) and Springer Nature B.V. 2022

\begin{abstract}
With the rapid development of Internet techniques in China, more and more Chinese middle-aged and older adults have begun to use the Internet for their daily social interactions, and the resulting online social capital may affect their health. Using data from the Chinese General Social Survey of $2017(n=7733$, aged 45-90 years old), this study investigated the influence of online social capital on the health of middle-aged and older adults in China, and the Heckman sample selection model was used to address potential sample selection bias in Internet use. The results show that number of online contacts significantly improved the physical health of middle-aged and older adults, while the level of depression was significantly reduced by online closeness of non-specific relationships, but more online interactions may slightly increase their depression. Furthermore, more online contacts were associated with elevated physical health among male, rural, less-educated and middleaged adults, while more online closeness of non-specific relationships was associated with less depression in almost all subgroups. Online social capital can improve the health of middle-aged and older adults in China, so we should help increase older adults' access to the Internet and improve their Internet skills to give full play to the positive health effect of online social capital. However, it should be alert to the negative health consequences caused by excessive Internet use.
\end{abstract}

Keywords Online social capital · Middle-aged and older adults · Health outcomes · Heckman sample selection model · China

Junfeng Jiang

jiang0111@ccnu.edu.cn

Jiang Song

007823@yzu.edu.cn

1 School of Sociology, Central China Normal University, No.152 Luoyu Road, Wuhan 430079, China

2 Business School, Yangzhou University, Yangzhou, China 


\section{Introduction}

Influenced by the baby boom of the 1960s, China's population will become aging at its peak in the next several years. By the end of 2020, the number of people over 60 years old in China was 264 million, accounting for $18.9 \%$ of the total population (Ning, 2021); and this number is predicted to be over 300 million by the end of 2025 (MCA, 2020). Middle-aged and older adults are in poor health and at high risks of various chronic diseases, such as cardiovascular disease and depression. Thus, this accelerated aging trend will undoubtedly increase the burden on the state and families in terms of elderly healthcare. On the other hand, over the past several years, the rapid development of Internet techniques has hugely reshaped the way people communicate with each other, more and more middle-aged and older adults have also joined the army of Internet users. As of December 2020, the total number of Chinese Internet users is 989 million, among which more than 250 million are over the age of 50 (CIINC, 2021). In the context of active aging policy and popularity of the Internet, Internet use has become more and more common in one's later life. This social fact has a profound impact on middle-aged and older adults' daily lifestyles, which has been confirmed to have some health consequences (Wang et al., 2019a, b; Zhao \& Liu, 2020).

Two main mechanisms from Internet use to individual health have been reported. One mechanism thinks that Internet use promotes health by increasing personal social interaction, leisure and entertainment, while the other believes Internet use helps users acquire health related information and resources to improve their health (Lu \& Wang, 2020; Yang \& He, 2020). Evidence from China suggests that Internet use can help improve both physical and mental health of the middle-aged and older adults (L. Wang, 2018; Wang et al., 2019a, b; Zhao \& Liu, 2020), because Internet use largely increases their learning behavior (Zhao \& Liu, 2020), leisure and entertainment (L. Wang, 2018) and stock of social capital (Liu et al., 2020; Lyu \& Sun, 2021). Evidence from other countries also shows that Internet use improves older adults' mental health mainly by increasing their online social connections and access to health information (Cotten et al., 2012; Szabo et al., 2019).

The present study focuses on how online social connection and its impact on offline interpersonal relationships affect the physical and mental health of Chinese middle-aged and older adults. In other words, we aimed to examine the health effect of online social capital. Due to the lack of available data, there are few studies investigating the relationship between online social capital and the health of middle-aged and older adults, and most prior studies only discuss the health effect of Internet use on older adults' health (Wang et al., 2019a, b; Zhao \& Liu, 2020) or focus on the health consequences of social network site (SNS) use among younger adolescents (Jiao, 2016; Song \& Jiang, 2021). However, less attention has been paid to online social capital and its health consequences among middle-aged and older adults. Furthermore, prior studies only evaluate the health effect of online social capital among those who have access to the Internet; this will lead to a sample selection bias, because those who do not use 
the Internet are excluded from the evaluation, while some factors that influence Internet use may also relate to individual health. In view of this, the present study used nationally representative survey data based on the Heckman sample selection model to estimate the health effects of online social capital among Chinese middle-aged and older adults.

\section{Literature Review and Research Hypotheses}

\section{Social Capital and its Health Effects}

Since Bourdieu and Coleman put forward the concept of social capital (Bourdieu, 1986; Coleman, 1988), social capital has been considered as one of the most important social determinants of health (Kawachi et al., 1999; Moore \& Kawachi, 2017; Xue et al., 2020). Social capital can be understood as a kind of social resources such as trust and norms of reciprocity embedded in personal social networks, which is produced by the stable connection between individuals or groups (Engbers et al., 2017; Lin, 2001). As a rule, social capital consists of structural and cognitive components, the former refers to the objective state and behaviors of people participating in socializing, while the latter is people's subjective cognition of interpersonal trust and reciprocity (Liu et al., 2016).

Numerous studies have reported that elements of social capital such as trust, norms of reciprocity, social interaction and participation are positively related to individual health (Rodgers et al., 2019; Xue et al., 2020), and this relationship has also been observed in middle-aged and older adults. Evidence from European countries indicates that interpersonal relationships and social participation can effectively increase the self-rated health (SRH) of middle-aged and older adults (Arezzo \& Giudici, 2017; Boen et al., 2020), while evidence from the United States also suggests that living in a community with more neighborhood social capital (e.g., a friendly, trusting, safe and integrated community environment) will make the elderly healthier (Cain et al., 2018; Villalonga-Olives et al., 2020). Evidence from five developing countries reports that neighborhood participation, trust and sense of security can improve the cognitive function of middle-aged and older adults, but it varies across countries (Jiang et al., 2020a, b). Other evidence from China is also mixed. For example, Liu et al. found that social participation could improve SRH and activities of daily living (ADL) in middle-aged and older adults, but it was not related to their depression (Liu et al., 2016); by contrast, other studies find that most social participation forms can help reduce older adults' depression in China (Li et al., 2020; Wang et al., 2019a, b).

\section{Online Social Capital: Definition and Measures}

Although evidence on the impact of social capital on health is growing, it is mixed and inconsistent, and most studies focused too much on the social capital based on offline contexts and neglected the growing online social capital. With 
the rapid development of Internet techniques, the Internet has increasingly become an important platform for people's socializing, and online social capital based on SNS use has become increasingly rich (Spottswood \& Wohn, 2020). According to the social capital theory, SNS use has become an indispensable means to build and maintain social relations in recent years (Ahmad et al., 2016; Lin, 2001). We can not only regard the social relations and resources embedded in the Internet as a new form of social capital (Lin, 2001), but also think it is SNS use that fosters and increases personal social capital (Williams, 2019). Online social capital is usually expressed in the form of SNS use (Song \& Jiang, 2021), because people usually interact online through SNS to increase or strengthen their interpersonal relationships. However, online social capital cannot exist independently from reality, and it usually reflects social connections with family members, friends or colleagues rather than unfamiliar people, indicating the maintaining of existing offline social relationships rather than establishment of new relations. Thus, online and offline social connections or networks are usually overlapped, especially in China (Song \& Jiang, 2021). In addition, online social capital is proposed in the context of social capital theory adapting to Internet development, its conceptualization and operationalization in prior studies are also based on classical social capital theory (Lin, 2001; Maghsoudi et al., 2020). Therefore, the classical social capital theory is actually applicable to interpret online social capital and its health consequences.

However, the operationalization of online social capital has not reached a consensus in empirical studies. Many researchers believe online social capital refers to people's online community connections and the resulting trust and norms of reciprocity (Ellison et al., 2007; Maghsoudi et al., 2020). For instance, Maghsoudi et al. (2020) distinguish bonding and bridging online social capital; they think the bonding one includes the acquisition of trust and social support through online socializing, while the bridging one includes the sense of belonging to a larger group based on online socializing. For brevity, Song and Jiang (2021) only use online social contact intensity as the measure of online social capital. Furthermore, previous studies often discuss how SNS use or online social capital influences offline social connections (Ahmad et al., 2016; Ellison et al., 2007; Williams, 2019), but there is little recognition that such association is intrinsic to the social connection itself. That is to say, changes in offline interpersonal connections brought by SNS use should be regarded as a part of online social capital, rather than its consequences. Because SNS use mainly plays a role in maintaining offline social relationships (Song \& Jiang, 2021), and the shaping function on offline social relationships is its intrinsic attribute. Thus, the measure of online social capital should involve not only the scale and intensity of online social interaction, but also the impact of online interaction on people's social connections in offline life.

\section{Health Effects of Online Social Capital}

SNS use is the most important basis for the survival of online social capital, and numerous studies regard SNS use as the most core element of online social capital (Ellison et al., 2007; Maghsoudi et al., 2020; Song \& Jiang, 2021), so we first review 
the health effects of SNS use. Numerous studies report that more SNS use is related to better physical and mental health (Kontos et al., 2010; Nabi et al., 2013). SNS use contributes to health benefits by increasing social support, reducing psychological stress, maintaining interpersonal relationships, and promoting trust (Kontos et al., 2010; Oh et al., 2013). In addition, SNS use can also promote health by spreading health information, so it has been widely used in health behavior interventions (Lin et al., 2018; Yang, 2017). A recently published study reports that online social capital based on SNS use is useful to improve health when there is insufficient offline social capital (Song \& Jiang, 2021). Actually, the social connections that middleaged and older adults derive from SNS are similar to those of younger adults (Sinclair \& Grieve, 2017). Accordingly, the following hypothesis is proposed.

H1: Online social capital can help improve the health of middle-aged and older adults in China.

However, some studies on Internet addiction report that excessive SNS use can lead to Internet addiction and social disconnection, which will result in some negative health consequences (Caplan, 2010) especially psychological health (Maghsoudi et al., 2020). This paradoxical result is related to the motivation for using SNS, as lonely people are more motivated to "indulge" in SNS use to compensate for or forget their being neglected in the offline world, which will ultimately lead to negative mental health consequences (Jiao, 2016; Song et al., 2014). In addition, excessive SNS use is commonly associated with some unhealthy behaviors, such as sedentariness and prolonged screen use, which is detrimental to physical health (Shi et al., 2020; Venden et al., 2019) and weakens the positive health effects of online social capital. For example, prior studies report that excessive SNS use may damage individual health when offline social capital is sufficient (Song \& Jiang, 2021), it may also do harm to individual sleep quality and mental health (Venden et al., 2019), and more online social capital can even damage teenagers' mental health by increasing online risk exposures (Maghsoudi et al., 2020). The immunity of middleaged and older adults is usually weaker than the younger, so they are more vulnerable to unhealthy behaviors such as sedentariness and prolonged screen use. Accordingly, the following competing hypothesis is proposed.

$\mathrm{H} 2$ : Online social capital is detrimental to the health of middle-aged and older adults in China.

\section{Data and Methods}

\section{Data Source}

The data used in this study were mainly from the Chinese General Social Survey (CGSS) of 2017. The CGSS project is the first large-scale and continuous nationwide social survey program for adults aged 18 and over in China. Using a stratified multistage sampling design with unequal probabilities, CGSS covers almost all provinces and has become one of the most important databases for investigating China's social change and Chinese daily life. CGSS2017 is the newest round of CGSS and includes a new section on the Internet, which provides high-quality data 
for this study. Samples aged 45 to 90 years old were included in the present study, ${ }^{1}$ and samples with unclear Internet access $(n=364)$ were excluded. A total of 7733 samples were finally obtained, including 1030 samples with Internet access and others without.

\section{Variables}

The self-reported physical health (SRPH) and depression were used as two outcome variables. Respondents were asked to provide the subjective evaluation on their current physical health ( $1=$ very unhealthy, $2=$ less healthy, $3=$ fair, $4=$ healthier, $5=$ very healthy) and the frequency of depression over the past four weeks ( $1=$ never, $2=$ seldom, $3=$ sometimes, $4=$ often, $5=$ always $)$. A larger score represented a better physical health status or a higher level of depression. In prior studies, the single-item SRH and depression indicators have been widely used and verified to have good reliability and validity (Hu et al., 2017; Jiang \& Kang, 2019; Qi, 2014).

Frequency of online interaction, number of online contacts and online closeness of interpersonal relationships were used as measures of online social capital. Frequency of online interaction was measured using the frequency of online social interaction over the past one year, and the response options included the following: ' $1=$ never, $2=$ seldom, $3=$ sometimes, $4=$ =ften, $5=$ always'. Number of online contacts was measured using the daily average number of people the respondents contacted online, and the response options included the following: ' $1=$ none, $2=1-4$, $3=5-9,4=10-19,5=20-49,6=50$ or over'. Online closeness of interpersonal relationships included closeness of specific and non-specific relationships. Online closeness of non-specific relationships was measured using the question 'Do you become estranged from people around you because of Internet use?', which was assessed on a 5-point Likert scale ranging from ' $1=$ totally agree' to ' $5=$ strongly disagree'. Four items were used to measure online closeness of specific relationships, the respondents were asked to answer the influence of Internet use on the closeness with likeminded people, family members, good friends and colleagues, and all four items were assessed on a 5-point Likert scale ranging from ' 1 =become very distant' to '5=become very close'. Subsequently, the exploratory factor analysis (EFA) was used to obtain the closeness of specific relationships variable (Cronbach's $\alpha=0.867$, cumulative variance $=0.719)$.

Sex (male and female), age (45-90 years), residence (urban and rural), education $(1=$ illiteracy, 2 = primary school, $3=$ junior high school, $4=$ senior high school, $5=$ college or above), Internet age, online time weekly, and Internet skill were used as control variables. Internet age was a continuous variable obtained by subtracting the survey year from the year firstly using the Internet. Online time weekly was set from 0 to $84 \mathrm{~h}$ and other values were set as missing data. Internet skill consisted of four specific skills, including 'using computer to open the website', 'using smartphone to download and install APP', 'searching and finding information online' and 'being able to express opinions online', and the response options 1 to 5 indicated a

\footnotetext{
1 Samples aged over 90 years old were excluded to reduce the adverse impact of elderly sample's sparseness value on the accuracy of model analysis.
} 
range from totally disagree to totally agree. EFA was used to obtain the Internet skill variable (Cronbach's $\alpha=0.854$, cumulative variance $=0.699$ ). In addition, whether using the Internet and Internet penetration rate at the province level were also used, they would be introduced in detail in the following section. More details can be seen in Table 1.

\section{Specification of Econometric Model}

The ordered Logit (OLogit) and ordinary least squares (OLS) models were used to estimate the association between online social capital and the health of middleaged and older adults in China. In the above models, however, samples that had no Internet access were excluded from the analysis, because only those who used the Internet could report their online social capital levels. This will lead to a sample selection problem, because there may be correlations between some unobservable confounders related to Internet access and the error terms of online social capital in the estimation equation. The above two models cannot address the endogeneity problem caused by sample selection, because only the respondents with Internet access were included in the analysis. Thus, the Heckman sample selection model was subsequently used.

In the Heckman sample selection model, all of the middle-aged and older adults with and without Internet access $(n=7733)$ were included in the analysis. It should be noted that the sample selection model needs to include a restriction excluding variable (Chen, 2020), and this variable should be related to Internet access but not directly related to individual health. The development of Internet techniques in China has a huge regional variation, and the Internet penetration rate varies greatly across provinces, which is determined by the socioeconomic developmental level and many other macro factors. Thus, the Internet penetration rate at the province level in 2016 was used as the restriction excluding variable, because it directly influenced the probability of Internet access or use among middle-aged and older adults within specific provinces, and it was unlikely to directly influence their health outcomes, only by influencing their Internet use at the micro level. Accordingly, the Heckman sample selection model was set as follows.

$$
\begin{aligned}
& \text { use }_{i}=\gamma_{0}+\gamma_{1} \text { rate }_{i}+\gamma_{2} Z_{i}+\mu_{i} \\
& \text { health }{ }_{i}=\beta_{0}+\beta_{1} \text { online } S C_{i}+\beta_{2} X_{i}+\beta_{3} \lambda_{i}+\varepsilon_{i}
\end{aligned}
$$

A two-step estimation method was used in the above model, as it had a weaker assumption on the normal distribution of outcomes (Q. Chen, 2014; Heckman, 1979) and provided more statistical power for the first-step estimation. In the above equations, use $_{i}$ represented Internet use of individual $i$; $X_{i}$ denoted a series of control variables (sex, age, residence, education, Internet age, online time weekly and Internet skills); $Z_{i}$ was a subset of $X_{i}$ and included sex, age, residence and education, because these four variables were assumed to related to Internet use. rate $_{i}$ was the Internet penetration rate at the province level in 2016, which should be included only in the first-step equation. $\lambda_{i}$ was the Mills rate, it denoted the ratio of the cumulative 
Table 1 Descriptive information of variables used

\begin{tabular}{|c|c|c|c|c|c|}
\hline Variables & Code & Frequency & $\%$ & M & SD \\
\hline \multicolumn{6}{|l|}{ Control variables } \\
\hline \multirow[t]{2}{*}{ Sex } & male & 3670 & 47.5 & & \\
\hline & female & 4063 & 52.5 & & \\
\hline Age & & 7733 & & 61.16 & 10.60 \\
\hline \multirow[t]{2}{*}{ Residence } & urban & 4544 & 58.8 & & \\
\hline & rural & 3189 & 41.2 & & \\
\hline \multirow[t]{5}{*}{ Education } & illiteracy & 1422 & 18.4 & & \\
\hline & primary school & 2148 & 27.8 & & \\
\hline & junior high school & 2234 & 29.0 & & \\
\hline & senior high school & 1222 & 15.8 & & \\
\hline & college or above & 691 & 9.0 & & \\
\hline Internet age & & 910 & & 7.65 & 6.35 \\
\hline Online time weekly & & 996 & & 12.45 & 13.27 \\
\hline Internet skill & & 1002 & & 0.00 & 1.00 \\
\hline \multirow[t]{2}{*}{ Internet access } & yes & 1030 & 13.3 & & \\
\hline & no & 6703 & 86.7 & & \\
\hline Internet penetration rate & & 7733 & & 0.55 & 0.12 \\
\hline \multicolumn{6}{|l|}{ Online social capital } \\
\hline \multirow[t]{5}{*}{ Frequency of online interaction } & never & 92 & 9.0 & & \\
\hline & seldom & 156 & 15.2 & & \\
\hline & sometimes & 222 & 21.6 & & \\
\hline & often & 393 & 38.2 & & \\
\hline & always & 165 & 16.0 & & \\
\hline \multirow[t]{6}{*}{ Number of online contacts } & 0 & 92 & 9.1 & & \\
\hline & $1-4$ & 377 & 37.1 & & \\
\hline & $5-9$ & 266 & 26.2 & & \\
\hline & $10-19$ & 180 & 17.7 & & \\
\hline & $20-49$ & 60 & 5.9 & & \\
\hline & $\geq 50$ & 41 & 4.0 & & \\
\hline Online closeness of non-specific relationships & & 1021 & & 4.11 & 0.86 \\
\hline Online closeness of specific relationships & & 921 & & 0.00 & 1.00 \\
\hline \multicolumn{6}{|l|}{ Health outcomes } \\
\hline \multirow[t]{5}{*}{ SRPH } & very unhealthy & 513 & 6.6 & & \\
\hline & unhealthy & 1738 & 22.5 & & \\
\hline & fair & 2226 & 28.8 & & \\
\hline & healthy & 2440 & 31.6 & & \\
\hline & very healthy & 812 & 10.5 & & \\
\hline \multirow[t]{5}{*}{ Depression } & never & 2069 & 26.8 & & \\
\hline & seldom & 2633 & 34.1 & & \\
\hline & sometimes & 2078 & 26.9 & & \\
\hline & often & 781 & 10.1 & & \\
\hline & always & 154 & 2.0 & & \\
\hline
\end{tabular}

M: mean; SD: standard deviation. Internet characteristic variables (Internet age, online time weekly, and Internet skill) and online social capital variables were asked and answered only when the respondents used the Internet, so the sample size was small $(n=1030)$. Internet skill and online intimacy of strong ties were calculated using EFA, so the mean was 1 and standard deviation was 0 
distribution function to the density function, which was used to control for the heterogeneity that led to sample selection biases. online $S C_{i}$ was online social capital, $\gamma_{0}$ and $\beta_{0}$ were two intercepts, $\mu_{i}$ and $\varepsilon_{i}$ were two residual items. Stata version 14.0 was used to perform the above models, and they were all weighted to ensure the nationally representativeness of the results.

\section{Results}

\section{Basic Information}

Appendix 1 shows there were obvious differences in population characteristics and health status between the respondents who used the Internet and those who did not. Specifically, middle-aged and older adults being male and from urban areas were more likely to have access to the Internet than their counterparts. The respondents who had access to the Internet were about six years younger than those who did not. Internet access was also closely related to samples' education; less than $10 \%$ of the respondents with primary school education or below had access to the Internet, while nearly $30 \%$ of the respondents with college education or above had access to the Internet. The respondents who had access to the Internet had better physical and mental health than those who did not. Furthermore, Internet access was also closely related to the Internet penetration rate at the province level, and a higher Internet penetration rate predicted more access to the Internet.

\section{Results of OLogit and OLS Models}

Table 2 shows that only number of online contacts was significantly related to the SRPH of middle-aged and older adults, while frequency of online interaction and online closeness of interpersonal relationships were not related to their SRPH. Furthermore, we observed that more online contacts were related to better SRPH of the respondents, whether controlling for demographics or not; compared to samples with no online contact, those with $\geq 50$ online contacts were more likely to have better SRPH $(\mathrm{OR}=2.500, p<0.01)$. By contrast, with Internet characteristic variables controlled for, the positive effect of online contacts on SRPH became smaller; compared to samples with no online contact, samples with 20-49 online contacts were twice as likely to have better SRPH $(\mathrm{OR}=2.023, p<0.1)$.

Online social capital was significantly associated with the depression of middle-aged and older adults in China. Table 3 suggests that more online contacts and online closeness of non-specific relationships were consistently related to less depression, whether controlling for demographics and Internet characteristics or not. Compared to samples with no online contact, samples with 20-49 online contacts were less likely to be depressive ( $\mathrm{OR}=0.418-0.465, p<0.1)$; every additional unit of online closeness of non-specific relationships reduced the probability of being depressive by $24.4 \%-28.3 \% \quad(\mathrm{OR}=0.717-0.756$, $p<0.01)$. By contrast, online interaction was related to depression only when 
Table 2 Impacts of online social capital on Chinese middle-aged and older adults' physical health: based on OLogit model

\begin{tabular}{|c|c|c|c|c|c|c|}
\hline & \multicolumn{2}{|l|}{ Model 1} & \multicolumn{2}{|l|}{ Model 2} & \multicolumn{2}{|l|}{ Model 3} \\
\hline & OR & R_SE & OR & R_SE & OR & R_SE \\
\hline Online interaction & 1.000 & 0.078 & 0.975 & 0.078 & 0.941 & 0.077 \\
\hline \multicolumn{7}{|l|}{ Online contacts (ref: 0 ) } \\
\hline $1-4$ & $1.714^{\wedge}$ & 0.499 & $1.802 *$ & 0.489 & $1.710^{\wedge}$ & 0.533 \\
\hline $5-9$ & $1.965^{*}$ & 0.628 & $1.845^{*}$ & 0.573 & 1.575 & 0.520 \\
\hline $10-19$ & $1.918^{\wedge}$ & 0.665 & $1.782^{\wedge}$ & 0.615 & 1.592 & 0.579 \\
\hline $20-49$ & $2.762 * *$ & 1.080 & $2.489^{*}$ & 0.945 & $2.023^{\wedge}$ & 0.851 \\
\hline$\geq 50$ & $3.105 * *$ & 1.273 & $2.500^{*}$ & 1.017 & 1.704 & 0.704 \\
\hline Online closeness of non-specific relationships & 0.950 & 0.086 & 1.019 & 0.092 & 1.021 & 0.101 \\
\hline Online closeness of specific relationships & 1.037 & 0.090 & 1.013 & 0.091 & 0.993 & 0.095 \\
\hline Sex (ref: male) & & & $0.690 *$ & 0.106 & $0.731^{*}$ & 0.113 \\
\hline Age & & & $0.962 * * *$ & 0.009 & $0.968 * *$ & 0.009 \\
\hline Residence (ref: rural) & & & 1.054 & 0.252 & 1.063 & 0.272 \\
\hline Education & & & $1.231 *$ & 0.118 & 1.097 & 0.121 \\
\hline Internet age & & & & & 0.994 & 0.014 \\
\hline Online time weekly & & & & & 0.995 & 0.006 \\
\hline Internet skill & & & & & $1.531 * * *$ & 0.176 \\
\hline \multicolumn{7}{|l|}{ Intercept } \\
\hline cut point 1 & -3.316 & 0.543 & -4.911 & 0.716 & -5.112 & 0.794 \\
\hline cut point 2 & -1.466 & 0.523 & -3.031 & 0.689 & -3.354 & 0.772 \\
\hline cut point 3 & 0.135 & 0.512 & -1.376 & 0.683 & -1.624 & 0.756 \\
\hline cut point 4 & 2.105 & 0.514 & 0.646 & 0.687 & 0.445 & 0.756 \\
\hline Pseudo_R ${ }^{2}$ & 0.007 & & 0.023 & & 0.033 & \\
\hline $\mathrm{n}$ & 905 & & 901 & & 777 & \\
\hline
\end{tabular}

$* * * p<0.001, * * p<0.01, * p<0.05, \wedge p<0.1$. OR: odds ratio, R_SE: robust standard error. The reference setting was the same below

other covariates were controlled for; the respondents with more online interactions in turn had a higher probability of being depressive $(\mathrm{OR}=1.215, p<0.05)$. With other variables controlled for, online closeness of specific relationships was not related to depression.

To test whether the above results are robust and to prepare for the following Heckman sample selection model, we then used OLS model to estimate the association between online social capital and Chinese middle-aged and older adults' health. Table 4 displays that with other variables controlled for, more online contacts were related to better SRPH and less depression $(b=0.417, p<0.05 ; b=-0.346, p<0.1$; respectively), more online closeness of non-specific relationships was related to less depression $(b=-0.156, p<0.001)$, but more online interactions were related to more depression $(b=0.102, p<0.05)$. These results were highly consistent with the results reported in Tables 2 and 3 . 
Table 3 Impacts of online social capital on Chinese middle-aged and older adults' depression: based on OLogit model

\begin{tabular}{|c|c|c|c|c|c|c|}
\hline & \multicolumn{2}{|l|}{ Model 1} & \multicolumn{2}{|l|}{ Model 2} & \multicolumn{2}{|l|}{ Model 3} \\
\hline & OR & R_SE & OR & R_SE & OR & R_SE \\
\hline Online interaction & 1.069 & 0.092 & 1.119 & 0.096 & $1.215^{*}$ & 0.109 \\
\hline \multicolumn{7}{|l|}{ Online contacts } \\
\hline $1-4$ & 0.824 & 0.224 & 0.753 & 0.192 & 0.743 & 0.222 \\
\hline $5-9$ & 0.786 & 0.246 & 0.749 & 0.225 & 0.756 & 0.249 \\
\hline $10-19$ & 0.571 & 0.201 & 0.584 & 0.208 & 0.665 & 0.254 \\
\hline $20-49$ & $0.418^{*}$ & 0.180 & $0.442^{\wedge}$ & 0.186 & $0.465^{\wedge}$ & 0.207 \\
\hline$\geq 50$ & 0.596 & 0.268 & 0.704 & 0.327 & 0.785 & 0.413 \\
\hline Online closeness of non-specific relationships & $0.756^{* *}$ & 0.061 & $0.744 * * *$ & 0.061 & $0.717 * * *$ & 0.067 \\
\hline Online closeness of specific relationships & $0.867^{\wedge}$ & 0.072 & 0.897 & 0.075 & 0.906 & 0.082 \\
\hline Sex & & & $1.296^{\wedge}$ & 0.205 & 1.243 & 0.196 \\
\hline Age & & & $0.977 *$ & 0.009 & $0.969 * *$ & 0.010 \\
\hline Residence & & & 0.989 & 0.190 & 1.386 & 0.290 \\
\hline Education & & & $0.706 * * *$ & 0.063 & $0.803^{*}$ & 0.081 \\
\hline Internet age & & & & & $0.966^{*}$ & 0.015 \\
\hline Online time weekly & & & & & 1.001 & 0.006 \\
\hline Internet skill & & & & & $0.732^{*}$ & 0.094 \\
\hline \multicolumn{7}{|l|}{ Intercept } \\
\hline cut point 1 & -1.881 & 0.454 & -3.901 & 0.662 & -3.916 & 0.759 \\
\hline cut point 2 & -0.487 & 0.446 & -2.442 & 0.654 & -2.476 & 0.751 \\
\hline cut point 3 & 1.443 & 0.464 & -0.462 & 0.654 & -0.363 & 0.758 \\
\hline cut point 4 & 3.469 & 0.562 & 1.565 & 0.720 & 1.612 & 0.837 \\
\hline Pseudo_R ${ }^{2}$ & 0.016 & & 0.037 & & 0.056 & \\
\hline $\mathrm{n}$ & 903 & & 899 & & 776 & \\
\hline
\end{tabular}

$* * * p<0.001, * * p<0.01, * p<0.05, \wedge p<0.1$. OR: odds ratio, R_SE: robust standard error

\section{Results of Heckman Sample Selection Model}

Table 5 shows that, in the Heckman sample selection model, the Mills rate $\lambda$ in both models was statistically significant, so there were heterogeneities caused by sample selection biases, and the estimations in Heckman sample selection model were more reliable. More specifically, online interaction did not influence middleaged and older adults' SRPH, but more online interactions increased their depression more or less $(b=0.056, p<0.1)$. More online contacts significantly promoted samples' SRPH $(b=0.454, p<0.05)$, but it no longer influenced their depression. Online closeness of non-specific relationships obviously reduced samples' depression $(b=-0.126, p<0.001)$, but it still did not influence their SRPH. Also, online closeness of specific relationships still did not influence middle-aged and older adults' SRPH and depression. 
Table 4 Impacts of online social capital on Chinese middle-aged and older adults' health: based on OLS model

\begin{tabular}{|c|c|c|c|c|}
\hline & \multicolumn{2}{|c|}{ Model 1: SRPH } & \multicolumn{2}{|c|}{ Model 2: depression } \\
\hline & $\mathrm{b}$ & R_SE & $\mathrm{b}$ & R_SE \\
\hline Online interaction & -0.038 & 0.039 & $0.102 *$ & 0.041 \\
\hline \multicolumn{5}{|l|}{ Online contacts } \\
\hline $1-4$ & $0.278^{\wedge}$ & 0.158 & -0.132 & 0.143 \\
\hline $5-9$ & 0.225 & 0.164 & -0.109 & 0.154 \\
\hline $10-19$ & 0.248 & 0.178 & -0.163 & 0.177 \\
\hline $20-49$ & $0.417 *$ & 0.200 & $-0.346^{\wedge}$ & 0.197 \\
\hline$\geq 50$ & 0.331 & 0.206 & -0.111 & 0.236 \\
\hline Online closeness of non-specific relationships & 0.017 & 0.047 & $-0.156^{* * *}$ & 0.044 \\
\hline Online closeness of specific relationships & 0.008 & 0.047 & -0.043 & 0.042 \\
\hline Sex & $-0.137^{\wedge}$ & 0.075 & 0.076 & 0.075 \\
\hline Age & $-0.017 * * *$ & 0.005 & $-0.014 * *$ & 0.005 \\
\hline Residence & 0.066 & 0.119 & $0.192^{\wedge}$ & 0.104 \\
\hline Education & 0.053 & 0.051 & $-0.117 *$ & 0.050 \\
\hline Internet age & -0.004 & 0.007 & $-0.018^{*}$ & 0.007 \\
\hline Online time weekly & -0.003 & 0.003 & 0.000 & 0.003 \\
\hline Internet skill & $0.205^{* * *}$ & 0.053 & $-0.134^{*}$ & 0.059 \\
\hline Intercept & $4.219 * * *$ & 0.369 & & \\
\hline $\mathrm{R}^{2}$ & 0.085 & & 0.128 & \\
\hline $\mathrm{n}$ & 777 & & 776 & \\
\hline
\end{tabular}

$* * * p<0.001, * * p<0.01, * p<0.05, \wedge p<0.1 . \mathrm{b}:$ coefficient, R_SE: robust standard error

Compared to the Heckman sample selection model, it is obvious that OLS model seemed to not only overestimate the effect of online interaction on the increase of samples' depression, but overestimate the effect of online contacts and closeness of non-specific relationships on the reduction of their depression. Because there is a selection effect in Internet use, people whose social needs are not met in offline life may use the Internet more for socializing, so an observational analysis may overstate the increased effect of online interaction on depression. The Heckman sample selection model can overcome this selection effect to some extent and the estimated effect reduced by nearly half (from 0.102 to 0.056). The same is true for the overestimation of online closeness; the positive mental health effect of online closeness is exaggerated due to the selection of online interaction among those with poorer mental health.

\section{Additional Analysis: Group Heterogeneities}

The influence of online social capital on the physical and mental health of middle-aged and older adults in China is obviously different in different subgroups. 
Table 5 Impacts of online social capital on Chinese middle-aged and older adults' health: based on Heckman sample selection model

\begin{tabular}{|c|c|c|c|c|}
\hline & \multicolumn{2}{|c|}{ Model 1: SRPH } & \multicolumn{2}{|c|}{ Model 2: depression } \\
\hline & $\mathrm{b}$ & SE & $\mathrm{b}$ & SE \\
\hline Online interaction & -0.026 & 0.035 & $0.056^{\wedge}$ & 0.034 \\
\hline \multicolumn{5}{|l|}{ Online contacts } \\
\hline $1-4$ & $0.241^{\wedge}$ & 0.147 & -0.021 & 0.144 \\
\hline $5-9$ & 0.202 & 0.157 & 0.021 & 0.155 \\
\hline $10-19$ & 0.206 & 0.167 & -0.030 & 0.165 \\
\hline $20-49$ & $0.454^{*}$ & 0.198 & -0.184 & 0.196 \\
\hline$\geq 50$ & $0.387^{\wedge}$ & 0.227 & -0.092 & 0.227 \\
\hline $\begin{array}{l}\text { Online closeness } \\
\text { of non-specific } \\
\text { relationships }\end{array}$ & 0.025 & 0.041 & $-0.126^{* * * *}$ & 0.041 \\
\hline $\begin{array}{l}\text { Online closeness of } \\
\text { specific relation- } \\
\text { ships }\end{array}$ & -0.025 & 0.037 & -0.049 & 0.036 \\
\hline Control variables & $\sqrt{ }$ & & $\sqrt{ }$ & \\
\hline Intercept & $4.668 * * *$ & 0.477 & $1.810 * * *$ & 0.517 \\
\hline$\lambda$ & $-0.552^{\wedge}$ & 0.286 & $1.259 * * *$ & 0.321 \\
\hline $\mathrm{n}$ & 7470 & & 7469 & \\
\hline
\end{tabular}

$* * * p<0.001, * * p<0.01, * p<0.05, \wedge p<0.1$. b: coefficient, SE: standard error

Appendix 2 shows that online contacts had a stronger positive effect on the SRPH of middle-aged and older adults being males, being younger, living in rural areas and less-educated (a weaker positive effect on the SRPH of those being females, being older, living in urban areas and well-educated). In addition, online interaction had a negative effect on SRPH in more educated samples $(b=-0.108$, $p<0.05$ ), while online closeness of specific relationships also had a negative effect on SRPH in rural samples $(b=-0.241, p<0.05)$.

By contrast, Appendix 3 shows that online interaction only increased the level of depression in male and younger samples $(b=0.126, p<0.01 ; b=0.093$, $p<0.1$; respectively). Online contacts only reduced the level of depression in male samples $(b=-0.484, p<0.1)$. While online closeness of non-specific relationships could reduce depression in all subgroups except the subgroup with more education.

\section{Discussion}

In the context of rapid development of China's Internet and aging society, the present study used the latest national survey data to examine the impact of online social capital on the physical and mental health of Chinese middle-aged and older adults for the first time. We found that middle-aged and older adults with access to the Internet had better physical and mental health than those without, and online social capital indeed improved middle-aged and older adults' physical and mental 
health. The size of online socializing was mainly related to physical health benefits, while online closeness of non-specific relationships mainly helped promote their mental health. By contrast, the phenomenon that more online interactions were related to elevated depression was partly attributed to the sample selection. Furthermore, the influence of online social capital on health was different among samples' with different sex, age, residence and education. Accordingly, the aforementioned hypotheses can only be supported on specific online social capital elements; online social networking size and closeness of interpersonal relationships play positive roles in physical and mental health promotion respectively (supporting H1), while more online interactions may slightly worsen the mental health of Chinese middle-aged and older adults (supporting H2).

Prior studies have already reported that diverse resources embedded in heterogeneous social networks usually bring more benefits than homogenous ones in terms of physical health promotion (Moore \& Kawachi, 2017; Rostila, 2010), and our results suggest this view is also applicable to the research on online social capital and health. The physical health effect of online contacts number is much stronger than that of online interaction frequency and the resulting close connections, because online interaction with more people brings more heterogeneous information and resources, which help older adults maintain and promote their physical health. For example, compared with resources embedded in homogenous networks, those embedded in heterogeneous networks can help patients obtain health information and medical resources more conveniently (Kawachi et al., 2013). On the other hand, online social interaction and related social closeness usually mean the increase or reinforcement of strong ties; they can help promote the mental health of middle-aged and older adults, because affinity is the most crucial factor for older adults' mental health promotion (Jiang et al., 2020a, b; Perkins et al., 2013. In the unique Chinese contexts, the non-specific "people around" usually refer to strong ties from which one can receive enough social support, rather than weak ties (Delhey et al., 2011), so an improved connection with people around can increase mental health benefits. Based on the above evidence, we believe $\mathrm{H} 1$ was supported.

However, more online interactions and the resulting close connections usually increase the intensity of strong ties rather than increasing contacts with more heterogeneous people or weak ties (Song \& Jiang, 2021). Just as some studies have reported, such an increase in homogeneous resources has fewer benefits in maintaining a healthy body (Moore \& Kawachi, 2017; Villalonga-Olives \& Kawachi, 2019), which is in line with our results. Similarly, prior studies have also reported that excessive online socializing may lead to negative mental health consequences (Song et al., 2014; Venden et al., 2019), and problematic social media use is related to elevated loneliness among the elderly (Meshi et al., 2020), because excessive online socializing may result from lacking offline social connections or interactions. It has been confirmed that there is a negative association between online socializing and offline community-based social capital, because excessive SNS use may squeeze time spent interacting with neighbors or friends (Hage et al., 2016; J. Song \& Jiang, 2021). Thus, middle-aged and older adults should pursue the positive consequences brought by online socializing such as the promotion of 
intimate relationships, rather than blindly pursuing excessive social interactions. Similarly, heterogeneous relationships associated with using the Internet to connect with more people rarely produce positive mental health benefits, because the mental health in middle-aged and older adults usually benefits more from strong ties (Perkins et al., 2013) rather than weak ties. Based on the above evidence, we conclude that $\mathrm{H} 2$ is also supported to some extent.

When it comes to the impact of online socializing size on the health of middleaged and older adults, the marginal advantage effect may simultaneously appears in both health advantaged and disadvantaged groups. Males and middle-aged adults are health advantaged groups, and their online social capital has more instrumental functions or purposes such as building or maintaining interpersonal relationships in the workplace, which is more helpful for them to acquire health resources and benefits (Kawachi et al., 2013). Although rural and less educated middle-aged and older adults belong to health disadvantaged groups, they have gained more marginal benefits in SNS use, which provides some insights for narrowing the health inequality caused by digital gap. Additionally, most of the well-educated middle-aged and older adults in CGSS2017 should be social elites belonging to the upper class, and excessive online socializing may squeeze too much time and opportunities for them to acquire other resources that can bring more benefits, which leads to negative health consequences. Rural samples own more bonding social capital (Jiang \& Kang, 2019), and the health benefits obtained from online socializing may be far fewer than those obtained from face-to-face socializing for them, so the health effect of online social capital may be weak or even negative because of this squeeze effect (Song \& Jiang, 2021). Similarly, the instrumental resources that male and middleaged groups gain from online socializing also contribute to their mental health promotion. However, the elevated closeness brought by online socializing cannot bring sufficient mental health benefits for well-educated middle-aged and older adults, because it squeezes too much time and opportunities to acquire other resources that can bring more mental health benefits.

\section{Implications and Limitations}

The aforementioned results provide some policy implications. First, in the context of aging and increasing burden of disease, the rapid development of Internet techniques provides some supports to address these problems. We should continue to develop the Internet and provide more access to the Internet for rural and less educated middle-aged and older adults, so as to make it a powerful weapon for the unhealthy to seek health equity and narrow the digital gap in modern society. Second, the distinct effects of different online social capital forms on health, as well as some unique health problems of middle-aged and older adults, deserve more attention. For example, for those with poor physical health, more opportunities should be provided to increase their online socializing with diverse groups so as to help them acquire useful health information and resources; for those with poor mental health, more chances should be provided to increase their online socializing with close people so as to strengthen their 
strong ties. Finally, the relationship between online and offline socializing should be focused; excessive online socializing is not encouraged to avoid squeezing too much time spent in offline socializing and its potential negative health consequences.

There are at least three limitations to this study. First, because the cross-sectional survey data are used, there may be simultaneity bias in the estimation of impact of online social capital on middle-aged and older adults' health, and it is also hard to investigate the temporal change in this impact. Second, there is no widely acknowledged and used online social capital scale, so we can only measure online social capital based on classical social capital theory and some prior studies, which may lead to some measurement errors. Finally, two health outcomes used are self-reported and single-item, which may also result in some measurement errors. Thus, further work is needed to discuss this topic.

\section{Appendix 1}

Table 6

Table 6 Group differences in Internet access among Chinese middle-aged and older adults

\begin{tabular}{|c|c|c|c|c|c|}
\hline Variables & Groups & $\begin{array}{l}\text { No access to } \\
\text { the Internet }\end{array}$ & $\begin{array}{l}\text { Access to the } \\
\text { Internet }\end{array}$ & $\mathrm{T} / \chi^{2}$ test & $p$ value \\
\hline \multirow[t]{2}{*}{ Sex } & male & 85.6 & 14.4 & 6.55 & 0.011 \\
\hline & female & 87.6 & 12.4 & & \\
\hline Age & & 61.97 & 55.95 & 17.30 & $<0.001$ \\
\hline \multirow[t]{2}{*}{ Residence } & rural & 93.7 & 6.3 & 231.42 & $<0.001$ \\
\hline & urban & 81.8 & 18.2 & & \\
\hline \multirow[t]{5}{*}{ Education } & illiteracy & 98.8 & 1.2 & 565.92 & $<0.001$ \\
\hline & primary school & 93.6 & 6.4 & & \\
\hline & junior high school & 83.2 & 16.8 & & \\
\hline & senior high school & 75.9 & 24.1 & & \\
\hline & college or above & 71.1 & 28.9 & & \\
\hline Internet penetration rate & & 0.55 & 0.61 & -16.21 & $<0.001$ \\
\hline SRPH & & 3.12 & 3.47 & -9.68 & $<0.001$ \\
\hline Depression & & 2.29 & 2.10 & 5.66 & $<0.001$ \\
\hline
\end{tabular}

Percentage \% was reported for categorical variables, and mean value was reported for continuous variables 


\section{Appendix 2}

Table 7

Table 7 Heterogeneity in impact of online social capital on Chinese middle-aged and older adults' physical health: based on Heckman sample selection model

\begin{tabular}{|c|c|c|c|c|c|c|c|c|}
\hline & male & female & younger & older & urban & rural & $\begin{array}{l}\text { less educa- } \\
\text { tion }\end{array}$ & $\begin{array}{l}\text { more edu- } \\
\text { cation }\end{array}$ \\
\hline $\begin{array}{l}\text { Online } \\
\text { interac- } \\
\text { tion }\end{array}$ & -0.029 & -0.020 & -0.013 & -0.083 & -0.019 & -0.086 & 0.033 & $-0.108^{*}$ \\
\hline \multicolumn{9}{|c|}{ Online contacts } \\
\hline $1-4$ & $0.363^{\wedge}$ & 0.020 & 0.210 & $0.467 *$ & 0.226 & 0.399 & 0.320 & -0.062 \\
\hline $5-9$ & 0.323 & -0.021 & 0.297 & 0.171 & 0.163 & 0.587 & 0.215 & 0.008 \\
\hline $10-19$ & 0.326 & -0.027 & 0.246 & 0.407 & 0.154 & 0.578 & 0.158 & 0.023 \\
\hline $20-49$ & $0.540^{*}$ & 0.350 & $0.611^{*}$ & 0.318 & $0.399^{\wedge}$ & 0.690 & $0.740 *$ & 0.146 \\
\hline$\geq 50$ & $0.688^{*}$ & -0.067 & $0.472^{\wedge}$ & 0.336 & 0.270 & $1.463^{*}$ & $1.037^{*}$ & 0.051 \\
\hline $\begin{array}{l}\text { Online } \\
\text { closeness } \\
\text { of non- } \\
\text { specific } \\
\text { relation- } \\
\text { ships }\end{array}$ & 0.037 & 0.022 & -0.020 & 0.117 & 0.003 & 0.134 & 0.093 & -0.024 \\
\hline $\begin{array}{l}\text { Online } \\
\text { close- } \\
\text { ness of } \\
\text { specific } \\
\text { relation- } \\
\text { ships }\end{array}$ & -0.057 & 0.006 & -0.007 & -0.048 & 0.026 & $-0.241^{*}$ & -0.024 & -0.048 \\
\hline $\begin{array}{l}\text { Control } \\
\text { variables }\end{array}$ & $\sqrt{ }$ & $\sqrt{ }$ & $\sqrt{ }$ & $\sqrt{ }$ & $\sqrt{ }$ & $\sqrt{ }$ & $\sqrt{ }$ & $\sqrt{ }$ \\
\hline Intercept & $4.757 * * *$ & $4.301 * * *$ & $4.219 * * *$ & $3.734 * *$ & $4.761 * * *$ & $3.237 *$ & $4.127 * * *$ & $5.180^{* * * *}$ \\
\hline$\lambda$ & $-0.799^{\wedge}$ & -0.217 & -0.388 & -0.428 & -0.436 & -2.162 & -0.540 & -0.426 \\
\hline $\mathrm{n}$ & 3547 & 3992 & 3401 & 4068 & 4342 & 3127 & 5654 & 1815 \\
\hline
\end{tabular}

${ }^{* * *} p<0.001, * * p<0.01,{ }^{*} p<0.05, \wedge p<0.1$. Only coefficients and $\mathrm{p}$ value were reported to save space. Although the Mills rate $\lambda$ was not statistically significant in most subgroups, the Heckman sample selection model included more samples and had more statistical power 


\section{Appendix 3}

Table 8

Table 8 Heterogeneity in impact of online social capital on Chinese middle-aged and older adults' depression: based on Heckman sample selection model

\begin{tabular}{|c|c|c|c|c|c|c|c|c|}
\hline & male & female & younger & older & urban & rural & $\begin{array}{l}\text { less educa- } \\
\text { tion }\end{array}$ & $\begin{array}{l}\text { more edu- } \\
\text { cation }\end{array}$ \\
\hline $\begin{array}{l}\text { Online } \\
\text { interac- } \\
\text { tion }\end{array}$ & $0.126^{* *}$ & -0.033 & $0.093^{\wedge}$ & -0.019 & 0.036 & 0.119 & 0.036 & 0.072 \\
\hline \multicolumn{9}{|c|}{ Online contacts } \\
\hline $1-4$ & -0.265 & 0.374 & -0.101 & 0.027 & 0.077 & -0.374 & -0.223 & 0.265 \\
\hline $5-9$ & -0.103 & 0.264 & -0.124 & 0.226 & 0.096 & -0.288 & -0.110 & 0.148 \\
\hline $10-19$ & -0.151 & 0.234 & -0.124 & 0.009 & 0.038 & -0.288 & 0.105 & 0.003 \\
\hline $20-49$ & $-0.444^{\wedge}$ & 0.281 & -0.442 & 0.127 & -0.066 & -0.722 & -0.344 & -0.040 \\
\hline$\geq 50$ & $-0.484^{\wedge}$ & 0.501 & 0.050 & -0.349 & 0.003 & -0.532 & -0.207 & 0.031 \\
\hline $\begin{array}{l}\text { Online } \\
\text { closeness } \\
\text { of non- } \\
\text { specific } \\
\text { relation- } \\
\text { ships }\end{array}$ & $-0.139 * *$ & $-0.125^{*}$ & $-0.109^{\wedge}$ & $-0.178^{*}$ & $-0.129 * *$ & $-0.138^{\wedge}$ & $-0.185^{* *}$ & -0.088 \\
\hline $\begin{array}{l}\text { Online } \\
\text { close- } \\
\text { ness of } \\
\text { specific } \\
\text { relation- } \\
\text { ships }\end{array}$ & -0.055 & -0.029 & -0.066 & -0.023 & -0.047 & -0.037 & 0.000 & -0.062 \\
\hline $\begin{array}{l}\text { Control } \\
\text { variables }\end{array}$ & $\sqrt{ }$ & $\sqrt{ }$ & $\sqrt{ }$ & $\sqrt{ }$ & $\sqrt{ }$ & $\sqrt{ }$ & $\sqrt{ }$ & $\sqrt{ }$ \\
\hline Intercept & 1.195 & $2.411 * *$ & -2.114 & 1.575 & $1.898^{* *}$ & $3.335^{* *}$ & $3.622 * * *$ & 0.636 \\
\hline$\lambda$ & $1.742 * *$ & $0.803^{*}$ & $2.353 * *$ & 0.472 & $1.355^{* * *}$ & 0.267 & $1.028 * *$ & $1.383 * *$ \\
\hline $\mathrm{n}$ & 3546 & 3922 & 3400 & 4068 & 4341 & 3127 & 5654 & 1814 \\
\hline
\end{tabular}

${ }^{* * *} p<0.001, * * p<0.01, * p<0.05, \wedge p<0.1$ 
Acknowledgements We appreciate the support from the following two funds; the 70th Batch of China Postdoctoral Science Foundation: Impact of social capital on epidemic prevention and health of community residents during the COVID-19 epidemic (No. 2021M701364), and the National Social Science Fund: Researches on the quality of life of rural left-behind older adults in the setting of aging (No. 16BRK014).

\section{Declarations}

Conflict of Interest The authors declare that there is no conflict of interest.

Ethical Statement Not applicable.

\section{References}

Ahmad, S., Mustafa, M., \& Ullah, A. (2016). Association of demographics, motives and intensity of using social networking sites with the formation of bonding and bridging social capital in Pakistan. Computers in Human Behavior, 57, 107-114.

Arezzo, M. F., \& Giudici, C. (2017). The effect of social capital on health among European older adults: An instrumental variable approach. Social Indicators Research, 134(1), 153-166.

Boen, F., Pelssers, J., Scheerder, J., Vanbeselaere, N., Vos, S., Hurkmans, E., \& Fransen, K. (2020). Does social capital benefit older adults' health and well-being? The mediating role of physical activity. Journal of Aging \& Health, 32(7-8), 688-697.

Bourdieu, P. (1986). The forms of capital. Greenwood Press.

Cain, C. L., Wallace, S. P., \& Ponce, N. A. (2018). Helpfulness, trust, and safety of neighborhoods: Social capital, household income, and self-reported health of older adults. Gerontologist, 58(1), 4-14.

Caplan, S. E. (2010). A social skill account of problematic internet use. Journal of Communication, 55(4), 721-736.

Chen, Q. (2014). Advanced econometrics and Stata applications (second ed.). Higher Education Press.

Chen, Y. (2020). New perspectives on social capital. China Renmin University Press.

CIINC. (2021). The 47th China statistical report on internet development Beijing.

Coleman, J. S. (1988). Social capital in the creation of human-capital. American Journal of Sociology, 94, 95-120.

Cotten, S. R., Ford, G., Ford, S., \& Hale, T. M. (2012). Internet use and depression among older adults. Computers in Human Behavior, 28(2), 496-499.

Delhey, J., Newton, K., \& Welzel, C. (2011). How general is trust in "most people"? Solving the radius of trust problem. American Sociological Review, 76(5), 786-807.

Ellison, N. B., Steinfield, C., \& Lampe, C. (2007). The benefits of Facebook "friends:" social capital and college students' use of online social network sites. Journal of Computer-Mediated Communication, 12(4), 1143-1168.

Engbers, T. A., Thompson, M. F., \& Slaper, T. F. (2017). Theory and measurement in social capital research. Social Indicators Research, 132(2), 537-558.

Hage, E., Wortmann, H., Offenbeek, M., \& v., \& Boonstra, A. (2016). The dual impact of online communication on older adults' social connectivity. Information Technology \& People, 29(1), 31-50.

Heckman, J. J. (1979). Sample selection bias as a specification error. Econometrics, 47, 153-161.

Hu, A., Yang, X. Y., \& Luo, W. (2017). Christian identification and self-reported depression: Evidence from China. Journal for the Scientific Study of Religion, 56(4), 765-780.

Jiang, D., Hou, Y., Hao, J., Zhou, J., Jiang, J., \& Wang, Q. (2020a). Association between personal social capital and loneliness among widowed older people. International Journal of Environmental Research and Public Health, 17, e5799.

Jiang, J., \& Kang, R. (2019). Temporal heterogeneity of the association between social capital and health: An age-period-cohort analysis in China. Public Health, 172, 61-69.

Jiang, N., Wu, B., Lu, N., \& Dong, T. (2020b). Neighborhood-based social capital and cognitive function among older adults in five low- and middle-income countries: Evidence from the World Health 
Organization study on global AGEing and adult health. International Journal of Geriatric Psychiatry, 35, 365-375.

Jiao, K. (2016). Loneliness and the use of mobile internet: A case study of college students' WeChat use. Youth Studies, 4, 19-28.

Kawachi, I., Kennedy, B. P., \& Glass, R. (1999). Social capital and self-rated health: A contextual analysis. American Journal of Public Health, 89(8), 1187-1193.

Kawachi, I., Takao, S., \& Subramanian, S. V. (2013). Global perspectives on social capital and health. Springer.

Kontos, E. Z., Emmons, K. M., Puleo, E., \& Viswanath, K. (2010). Communication inequalities and public health implications of adult social networking site use in the United States. Journal of Health Communication, 15(S3), 216-235.

Li, Y., Lu, H., Cheng, Q., \& Gu, D. (2020). Association between social participation and depression among older adults in China. Population \& Development, 26(3), 86-97.

Lin, H.-C., Chen, Y. J., Chen, C.-C., \& Ho, W.-H. (2018). Expectations of social networking site users who share and acquire health-related information. Computers and Electrical Engineering, 69, $808-814$.

Lin, N. (2001). Social capital: A theory of social structure and action. Cambridge University Press.

Liu, G. G., Xue, X., Yu, C., \& Wang, Y. (2016). How does social capital matter to the health status of older adults? Evidence from the China health and retirement longitudinal survey. Economics and Human Biology, 22, 177-189.

Liu, Q., Pan, H., \& Wu, Y. (2020). Migration status, internet use, and social participation among middle-aged and older adults in China: Consequences for depression. International Journal of Environmental Research \& Public Health, 17, e6007.

Lu, H., \& Wang, B. (2020). Research on the influence mechanism of internet use on self-rated health: Based on data from the Chinese family panel studies of 2016. Journal of Sun Yet-Sen University, 60(3), 117-127.

Lyu, S., \& Sun, J. (2021). Internet use and self-rated health among Chinese older adults: The mediating role of social capital. Geriatrics Gerontology International, 21, 34-38.

Maghsoudi, R., Shapka, J., \& Wisniewski, P. (2020). Examining how online risk exposure and online social capital influence adolescent psychological stress. Computers in Human Behavior, 113, e106488.

Mca, C. (2020). The elderly population is expected to exceed 300 million, and the Ministry of Civil Affairs predicts that China will soon become a moderate aging society. From https://www.sohu. com/na/426947218_139908

Meshi, D., Cotten, S. R., \& Bender, A. R. (2020). Problematic social media use and perceived social isolation in older adults: A cross-sectional study. Gerontology, 66, 160-168.

Moore, S., \& Kawachi, I. (2017). Twenty years of social capital and health research: A glossary. Journal of Epidemiology \& Community Health, 71(5), 513-517.

Nabi, R. L., Prestin, A., \& So, J. (2013). Facebook friends with (health) benefits? Exploring social network site use and perceptions of social support, stress, and well-being. Cyberpsychology, Behavior and Social Networking, 16(10), 721-727.

Ning, J. (2021). The main data of the seventh national census. Beijing.

Oh, H. J., Lauckner, C., Boehmer, J., Fewins-Blis, R., \& Li, K. (2013). Facebooking for health: An examination into the solicitation and effects of health-related social support on social networking sites. Computers in Human Behavior, 29(5), 2072-2080.

Perkins, M. M., Ball, M. M., Kemp, C. L., \& Hollingsworth, C. (2013). Social relations and resident health in assisted living: An application of the convoy model. Gerontologist, 53, 495-507.

Qi, Y. (2014). Reliability and validity of self-rated general health. Chinese Journal of Sociology, 34(6), 196-215.

Rodgers, J., Valuev, A. V., Hswen, Y., \& Subramanian, S. V. (2019). Social capital and physical health: An updated review of the literature for 2007-2018. Social Science \& Medicine, 236, $1-12$.

Rostila, M. (2010). The facets of social capital. Journal for the Theory of Social Behaviour, 41, 308-326.

Shi, Z., Gu, J., \& Fu, Q. (2020). Social change and health inequality: An age-period-cohort analysis on the fifth transformation of disease. Sociological Studies, 6, 160-185.

Sinclair, T. J., \& Grieve, R. (2017). Facebook as a source of social connectedness in older adults. Computers in Human Behavior, 66, 363-369. 
Song, H., Zmyslinski-Seelig, A., Kim, J., Drent, A., Victor, A., Omori, K., \& Allen, M. (2014). Does Facebook make you lonely? A meta analysis. Computers in Human Behavior, 36, 446-452.

Song, J., \& Jiang, J. (2021). Online social capital, offline social capital and health: Evidence from China. Health \& Social Care in the Community in press.

Spottswood, E. L., \& Wohn, D. Y. (2020). Online social capital: Recent trends in research. Current Opinion in Psychology, 36, 147-152.

Szabo, A., Allen, J., Stephens, C., \& Alpass, F. (2019). Longitudinal analysis of the relationship between purposes of internet use and well-being among older adults. Gerontologist, 59(S1), 58-68.

Venden, P. G., Setti, I., Meulen, E., \& Das, M. (2019). Does social networking sites use predict mental health and sleep problems when prior problems and loneliness are taken into account? A population-based prospective study. Computers in Human Behavior, 93, 200-209.

Villalonga-Olives, E., Almansa, J., Knott, C. L., \& Ransome, Y. (2020). Social capital and health status: Longitudinal race and ethnicity differences in older adults from 2006 to 2014. International Journal of Public Health, 65, 291-302.

Villalonga-Olives, E., \& Kawachi, I. (2019). The dark side of social capital: A systematic review of the negative health effects of social capital. Social Science \& Medicine, 194, 105-127.

Wang, L. (2018). Research on the influence mechanism of internet use on the physical and mental health of the elderly: Based on data from the Chinese general social survey of 2013. Modern Economic Research, 4, 101-108.

Wang, R., Chen, Z., Zhou, Y., Shen, L., Zhang, Z., \& Wu, X. (2019a). Melancholy or mahjong? Diversity, frequency, type, and rural-urban divide of social participation and depression in middle- and old-aged Chinese: A fixed-effects analysis. Social Science \& Medicine, 238, e112518.

Wang, Y., Zhang, H., Feng, T., \& Wang, H. (2019b). Does internet use affect levels of depression among older adults in China? A propensity score matching approach. BMC Public Health, 19, e1474.

Williams, J. R. (2019). The use of online social networking sites to nurture and cultivate bonding social capital: A systematic review of the literature from 1997 to 2018. New Media \& Society, 21(11-12), 2710-2729.

Xue, X., Reed, W. R., \& Menclova, A. (2020). Social capital and health: A meta-analysis. Journal of Health Economics, 72, 1-16.

Yang, K., \& He, H. (2020). The impact of internet usage on health of residents: A study from the China labor-force dynamic survey 2016. Nankai Economic Studies, (3), 182-203.

Yang, Q. (2017). Are social networking sites making health behavior change interventions more effective? A meta-analysis. Journal of Health Communication, 22(3), 223-233.

Zhao, J., \& Liu, Z. (2020). Influence of internet use on the health of Chinese older people. Chinese Journal of Population Science, (5), 14-26.

Publisher's Note Springer Nature remains neutral with regard to jurisdictional claims in published maps and institutional affiliations. 